\title{
Metaplastic breast carcinoma with chondrosarcomatous differentiation: an unusual disease with a worse prognosis
}

\author{
Samuel Lalhruaizela ${ }^{1 *}$, Bhupendra Mehra ${ }^{2}$ \\ ${ }^{1}$ Assistant Professor, Department of Surgery, Zoram Medical College, Mizoram, India \\ ${ }^{2}$ Professor, Department of Surgery, Mahatma Gandhi Institute of Medical Sciences, Wardha, Maharashtra, India
}

Received: 10 February 2020

Accepted: 25 February 2020

*Correspondence:

Dr. Samuel Lalhruaizela,

E-mail: samuvuite@gmail.com

Copyright: $\odot$ the author(s), publisher and licensee Medip Academy. This is an open-access article distributed under the terms of the Creative Commons Attribution Non-Commercial License, which permits unrestricted non-commercial use, distribution, and reproduction in any medium, provided the original work is properly cited.

\begin{abstract}
Metaplastic breast carcinoma (MBC) has an incidence of $<1 \%$ of all breast cancers and MBC with chondrosarcomatous differentiation is even more rare, $<0.1 \%$ of all cases. The World Health Organization have classified MBC into pure epithelial-type and mixed epithelial and mesenchymal type. The epithelial-type MBC is subclassified into squamous cell carcinoma, adenosquamous carcinoma and adenocarcinoma with spindle cell differentiation; mixed type $\mathrm{MBC}$ is sub-classified into carcinosarcoma and carcinoma with osseous and chondroid metaplasia. Metaplastic carcinomas of the breast are characterized by large tumour size and rapid growth, and they are usually estrogen receptor, progesterone receptor, and HER2/neu negative and tend to have a worse prognosis than other triple negative breast cancers. There is a noteworthy increased risk of tumour recurrence and a worse prognosis with MBC compared with invasive lobular carcinoma and infiltrating duct carcinoma. We report a case of metaplastic carcinoma with extensive chondroid differentiation that is chondrosarcoma and chondroid metaplasia along with classic infiltrating duct carcinoma with involvement of ipsilateral axillary lymph nodes.
\end{abstract}

Keywords: Chondrosarcoma, Carcinosarcoma, Metaplastic, Mesenchymal

\section{INTRODUCTION}

Metaplastic breast carcinoma (MBC) is a rare malignancy characterized by various combinations of adenocarcinoma with mesenchymal and epithelial components. MBC accounts for $<1 \%$ of all breast carcinomas. ${ }^{1}$ Mesenchymal component in the form of chondrosarcoma, are the rarest primary malignancies of the breast found in $<0.1 \%$ of all cases. ${ }^{2}$ The World Health Organization have classified $\mathrm{MBC}$ into pure epithelial-type and mixed epithelial and mesenchymal type. The epithelial-type MBC is sub-classified into squamous cell carcinoma, adenosquamous carcinoma and adenocarcinoma with spindle cell differentiation; mixed type MBC is subclassified into carcinosarcoma and carcinoma with osseous and chondroid metaplasia. ${ }^{3}$ Metaplastic carcinomas of the breast are characterized by large tumour size and rapid growth, and are usually estrogen and progesterone receptors, along with HER2/neu negative having a worse prognosis than other triple negative breast cancers. There is a noteworthy increased risk of tumour recurrence and a worse prognosis with MBC compared with invasive lobular carcinoma and infiltrating duct carcinoma (IDC). ${ }^{4}$

\section{CASE REPORT}

Study reports a case of a 35 year old female with lump in the left breast since 3 months with no associated pain or nipple discharge. On examination, a hard lump measuring $5.5 \mathrm{~cm} \times 3 \mathrm{~cm}$ was seen in the upper outer quadrant of the left breast extending to the lower outer quadrant with no skin or chest wall involvement. There were multiple palpable axillary lymph nodes which were hard and fixed 
pertaining to the apical and anterior group of axillary lymph nodes. Core needle biopsy was done in the institute and reported as IDC with mucinous areas. The tumour was staged according to 8th Edition of American Joint Committee on Cancer (AJCC) TNM Staging as pT3N2aM0 (stage IIIA). A left modified radical mastectomy with axillary lymph node dissection was done and specimen was sent for histopathological examination and immunohistochemistry followed by chemotherapy and radiotherapy (Table 1).

Table 1: Patient characteristics.

\begin{tabular}{|l|l|}
\hline Clinical & $\begin{array}{l}\text { 35 year old women. } \\
\text { pT3N2aM0, BIRADS 5, 5.5 cm } \\
\times 3 \mathrm{~cm} \text { solid-liquid tumor, sharp } \\
\text { borders }\end{array}$ \\
\hline Surgery & $\begin{array}{l}\text { Modified radical mastectomy } \\
\text { with axillary lymph node } \\
\text { dissection (ALND) }\end{array}$ \\
\hline & $\begin{array}{l}\text { Metaplastic carcinoma of breast } \\
\text { with areas of infiltrating duct } \\
\text { carcinoma (NOS) with } \\
\text { mesenchymal component in the } \\
\text { (histopathological) } \\
\text { form of conventional } \\
\text { chondrosarcoma }\end{array}$ \\
\hline $\begin{array}{l}\text { Immuno- } \\
\text { histomchemistry }\end{array}$ & $\begin{array}{l}\text { ER (-), PR (-), Her2-neu (-) } \\
\text { (triple negative) }\end{array}$ \\
\hline $\begin{array}{l}\text { Adjuvant } \\
\text { chemotherapy }\end{array}$ & $\begin{array}{l}\text { Doxorubicin and } \\
\text { cyclophosphamide (6 courses) }\end{array}$ \\
\hline Radiotherapy & $\begin{array}{l}\text { 50 Gy, 25 fractions, 3 times in a } \\
\text { week }\end{array}$ \\
\hline
\end{tabular}

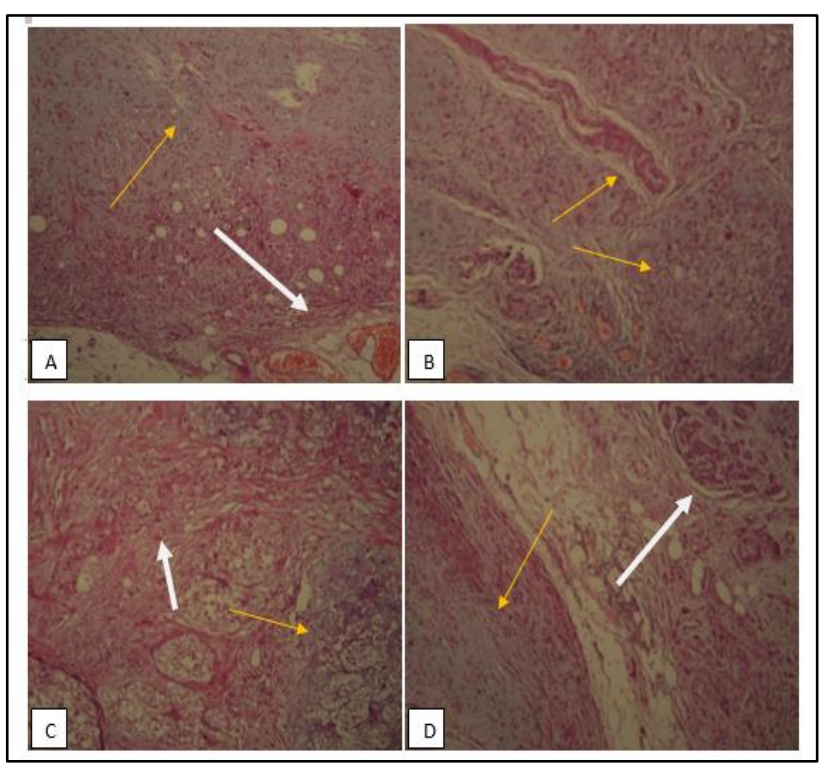

Figure 1: (A-D) Photomicrograph of tumor showing infiltrating duct carcinoma and metaplastic carcinoma with extensive chondroid differentiation that is chondrosarcoma focus.

(Hematoxylin and eosin staining) (yellow arrows - chondroid differentiation; mesenchymal areas, blue stain) (white arrowsinfiltrating duct carcinoma, red stain).
On histopathological examination, there was presence of tumour mass in the upper outer quadrant of the left breast extending to the lower quadrant in lower outer quadrant measuring $6.5 \times 3 \times 2.5 \mathrm{~cm}$. Tumour appeared to be 1.4 $\mathrm{cm}$ away from the skin and $0.2 \mathrm{~cm}$ away from the base of resection. 16 axillary lymph nodes were isolated, largest measuring $3 \mathrm{cms}$ in diameter with encapsulated external surface. Cut surface was grey white and homogenous. Histological examination showed metaplastic carcinoma of breast with areas of infiltrating duct carcinoma (NOS) and merging intimately with large areas of heterologous mesenchymal component in the form of conventional chondrosarcoma (Figure 1; A-D). Areas of in situ carcinoma were not seen. Nipple, areola was uninvolved. A total of 16 lymph nodes were isolated out of which 14 lymph nodes were positive for metastases. The tumour sections were subjected to a panel of immunohistochemical markers- ER (-), PR (-), HER-2 neu (-) (triple negative). With these morphological and immunohistochemical features, the diagnosis of metaplastic carcinoma (carcinosarcoma infiltrating duct carcinoma grade III and chondrosarcoma) was favoured.

\section{DISCUSSION}

The incidence of MBC is $<1 \%$ of all breast cancers and $\mathrm{MBC}$ and chondrosarcomatous differentiation is even more rare, $<0.1 \%$ of all cases. ${ }^{1,2}$ The designation of carcinosarcoma is used when the mesenchymal component is malignant. The commonest epithelial element is poorly differentiated duct carcinoma, NOS as in the present case. Metaplasia has also been reported in association with lobular, tubular, medullary and mucinous breast carcinoma. The popular theory explaining the histiogenesis of metaplastic components is through transformation of myoepithelial cells or a multipotent duct progenitor cell after p53 mutation. ${ }^{5}$ $\mathrm{MBC}$ rarely exhibits estrogen and progesterone receptors while the frequency of HER-2/neu over-expression ranges from negative to $33 \%$. The incidence of triple negative breast cancer is remarkably higher in MBC than in IDC. Other panel of markers comprise of S100, CK, EMA and vimentin. The tumour cells in chondrosarcomatous areas are diffusely reactive for S100, vimentin, focally positive for CK but negative for EMA; whereas in carcinomatous areas the tumour cells are diffusely positive for $\mathrm{CK}$ and $\mathrm{S} 100$ with focal positivity. ${ }^{5}$ Traditional chemotherapy and hormonal therapies for IDC are the current standard for $\mathrm{MBC}$, but future treatments are being considered as well. Novel strategies have emerged to target the non-epithelial component of MBC. One such method is the use of ifosfamide and etoposide for the carcinosarcoma subtype of MBC. ${ }^{6}$ Lastly, regardless of the type of surgery used to eradicate the tumour, adjuvant radiation should be considered as part of the multimodality therapy for MBC patients. Additional studies suggested that for $\mathrm{MBC}$ patients with tumours $5 \mathrm{~cm}$ or larger or having greater than 4 metastatic axillary lymph nodes, undergoing mastectomy and radiation therapy is beneficial, and this 
approach should certainly be used. ${ }^{7}$ Future studies with molecular techniques are currently being analyzed for genetic or epigenetic aberrations that might provide insight into the basis of the heterogeneity of the MBC. These efforts may one day identify novel therapies and realize the potential of targeted treatment in patients with MBC. ${ }^{8}$

Funding: No funding sources

Conflict of interest: None declared

Ethical approval: Not required

\section{REFERENCES}

1. Tavassoli FA. Classification of metaplastic carcinomas of the breast. Pathol Annu. 1992;27:89119.

2. Kurian KM, Nafussi A. Sarcomatoid/metaplastic carcinoma of the breast: a clinicopathological study of 12 cases. Histopathol. 2002;40:58-64.

3. Bocker W. WHO classification of breast tumors and tumors of the female genital organs: patholog and genetics. Verh Dtsch Ges Pathol. 2002;86:116-9.

4. Luini A, Aguilar M, Gatti G. Metaplastic carcinoma of the breast, an unusual disease with worse prognosis: the experience of the European Institute of Oncology and review of the literature. Breast Cancer Res Treat. 2007;101(3):349-53.

5. Fenyvesi A. A case of carcinoma of the breast with metaplasia to chondrosarcoma: light microscopic and immunohistochemical features. Arch Oncol. 2003;11:273-6.

6. Shah DR, Tseng WH, Martinez SR. Treatment options for metaplastic breast cancer. ISRN Oncol. 2012;70:61-2.

7. Lai HW, Tseng LM, Chang TW. The prognostic significance of metaplastic carcinoma of the breast (MCB) a case controlled comparison study with infiltrating ductal carcinoma. Breast. 2013;22(5):968-73.

8. Weigelt B, Eberle C, Cowell CF, Ng CK, Filho JS. Metaplastic breast carcinoma: more than a special type. Nat Rev Cancer. 2014;14:147-8.

Cite this article as: Lalhruaizela S, Mehra B.

Metaplastic breast carcinoma with

chondrosarcomatous differentiation: an unusual

disease with a worse prognosis. Int Surg J

2020;7:1277-9. 